\title{
Managing Complexity For Creating Breakthrough Inventions: Focusing On Collaboration Teams And Prior Art
}

\author{
Hee Jin Mun, Yonsei University, South Korea
}

Yerim Chung, Yonsei University, South Korea

\begin{abstract}
Inventing processes are often greatly complex, resulting in the difficulty of creating breakthrough inventions. But the relationship between the complexity of inventing and the creation of breakthrough inventions and ways of dealing with the complexity of inventing have received little research attention. This study focuses on the effect of coupling, one of the causes of complex inventing, on the likelihood of creating breakthrough inventions and suggests two moderating factors: the size of collaboration teams and the oldness of prior art. Based on U.S. granted patents in optical disc technology domains applied during 1997-2001, the empirical results showed the negative effect of coupling on the likelihood of creating breakthrough patents and the weakening moderating effect of the number of inventors involved in generating patents.
\end{abstract}

Keywords: Complex Inventing; Breakthrough Invention; Collaboration

\section{INTRODUCTION}

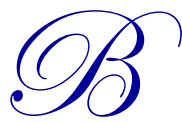

reakthrough inventions can impact hugely on firm innovation as well as economic growth. Thanks to earlier studies (Arts \& Veugelers, 2015; Schilling \& Green, 2011; Schoenmakers \& Duysters, 2010), researchers know somewhat about the origins of breakthrough inventions that "serve as the basis for any subsequent technical developments" (Ahuja \& Lampert, 2001, p. 523). But they have missed the point that inventing processes are highly complex, which is one of the obstacles that inventors confront (Maggitti, Smith, \& Katila, 2013).

According to research on recombinant search, inventors can create breakthrough inventions by recombining knowledge components in novel manners (Arts \& Veugelers, 2015; Schilling \& Green, 2011), a knowledge component which is "any fundamental bits of knowledge or matter that inventors might use to build inventions" (Fleming \& Sorenson, 2004, p. 910). However, knowledge components can be interdependent (Fleming \& Sorenson, 2001, 2004; Yayavaram \& Ahuja, 2008). Change in one component can affect the functionality of other interdependent components (Fleming \& Sorenson, 2004; Yayavaram \& Ahuja, 2008). The problem is that inventors with bounded rationality cannot predict all consequences coming from any minor change in highly interdependent components (Fleming \& Sorenson, 2004). As a result, creating breakthrough inventions with highly interdependent components is complex and thus likely to be a herculean task to inventors.

In this study, we argue that coupling aggregating interdependencies in the constituent knowledge components of an invention (Fleming \& Sorenson, 2004) negatively affects the likelihood of creating breakthrough inventions. Further, this study suggests two moderating factors. First, we focus on the size of collaboration teams for inventing. Inventors with bounded rationality may be able to relieve the complexity of inventing through technology-related social groups (Fleming \& Sorenson, 2001). This study argues that collaboration teams have more chances of reducing the complexity of inventing thanks to more diverse knowledge and experience and rigorous screening processes of them than those of lone inventors. Thus, as the size of collaboration teams increases, the negative effect of coupling on the likelihood of creating breakthrough inventions weakens. Second, we suggest the oldness of prior art of inventions. 
Most inventions are created based on prior art rather than "from scratch." Prior art is created at different time points (Heeley \& Jacobson, 2008; Katila, 2002; Nerkar, 2003). Because old knowledge can be the reliable cornerstone of knowledge creation (March, 1991) and the unexplored components of recently created prior art may complicate inventing processes (Katila, 2002), we argue that inventing based on old prior art is likely to weaken the negative effect of coupling on the likelihood of creating breakthrough inventions.

For empirical analysis, following previous studies regarding patents as inventions, this study focuses on U.S. granted patents closely related to optical disc technology applied during 1997-2001. Our empirical results showed that the coupling of patents negatively affects the likelihood that these patents become breakthrough. And we found that, as the number of inventors involved in creating patents increases, the negative effect of coupling weakens. Based on the empirical results, this study provides understandings of and managerial implications for the complexity of inventing.

\section{THEORY AND HYPOTHESES}

The creation of novel ideas such as inventions "consists to a substantial extent of a recombination of conceptual and physical materials that were previously in existence" (Nelson \& Winter, 1982, p. 130). That is, inventions are created through combining knowledge components in novel ways. Therefore, invention can be regarded as a process of recombining knowledge components (Arts \& Veugelers, 2015; Fleming, 2001; Fleming \& Sorenson, 2001, 2004).

All knowledge components in existence can be used for invention (Fleming, 2001). However, individuals with bounded rationality have limitations on processing information and predicting outcomes of their activities (March \& Simon, 1993). They cannot know all extant knowledge components nor inventive outputs resulting from countless combinations of extant knowledge components ex ante (Fleming, 2001). If inventors consider for inventing knowledge components that they lack experience and expertise, they should invest great efforts and resources in order to manage difficulties resulting from understanding and integrating these distant components (Schilling \& Green, 2011). As a result, inventors usually conduct local recombination that knowledge components salient, proximal, and available for them are considered for inventing (Fleming, 2001; March, 1991).

Knowledge components are intertwined with each other (Fleming \& Sorenson, 2001, 2004; Yayavaram \& Ahuja, 2008). For example, aircraft engine control systems and engine designs evolve interdependently (Brusoni, Prencipe, \& Pavitt, 2001). Aggregating interdependencies in the constituent knowledge components of an invention determines this invention's coupling, "the degree to which components interact in determining the functionality of the overall invention" (Fleming \& Sorenson, 2004, p. 913). When the constituent knowledge components of an invention are highly coupled, minor change in only one component can lead the overall functionality of the invention to extremely fluctuate (Fleming \& Sorenson, 2001). In contrast, change in independent components - those with no coupling gradually affects the overall functionality of an invention.

If there is no coupling among knowledge components, local recombination is likely to go without hindrance during inventing. However, as knowledge components become coupled, inventors doing local recombination may make slow progress because local recombination is more effective in less complex inventing (Fleming \& Sorenson, 2004). Furthermore, processing interdependencies in knowledge components can be beyond the cognitive ability of inventors (March \& Simon, 1993). When inventors consider any change in one knowledge component, they should take into account possible effects of this change on other coupled components as well. The negative side of this consideration is that inventors will stop searching for better configurations when finding a satisfactory configuration (Yayavaram \& Ahuja, 2008) because further changes have no guarantee of finding more superior configurations or even may negatively affect the overall functionality of inventions due to unexpected interdependence among components. Consequently, inventors dealing with highly coupled components tend to resist exploratory changes that will take them away from current locally optimal configurations (Yayavaram \& Ahuja, 2008). They may spend their time and attention to predict and avoid or remove increasing subtle interactions among knowledge components rather than to explore new combinations. Thus, finding an extremely superior configuration of knowledge components becomes a matter of luck. Taken together, these arguments lead to the following hypothesis: 
Hypothesis 1: As more highly coupled components are combined, the likelihood of creating breakthrough inventions decreases.

\section{Collaboration Team}

There are heroic tales of lone inventors (Ahuja \& Lampert, 2001; Singh \& Fleming, 2010). However, recent research on invention suggests the two advantages of collaboration teams over lone inventors. First, inventors bring diverse knowledge and experience into a collaboration team and then interact with each other, which increases the number of configurations that the collaboration team can consider (Singh \& Fleming, 2010; Taylor \& Greve, 2006) and leads to more parallel processing of complex issues (Nonaka, 1994). Fleming and Sorenson (2004) argue that, if individuals conduct offline search in which they do recombination in their own mind (Gavetti \& Levinthal, 2000), they can reduce complexity resulting from highly coupled components. The increasing number of component configurations that team members can consider and more parallel processing of complexities are likely to increase the possibility that vaster and more elaborate offline search occurs in collaboration teams than does in lone inventors' mind. And this effect may be positively correlated with the size of collaboration teams.

Second, collaboration teams can have more rigorous screening processes for invention than lone inventors (Singh \& Fleming, 2010). Based on diverse knowledge and experience within collaboration teams, some team members are more likely to recall that they created inventions technologically similar to their current invention. And they can suggest to abandon or modify current invention approaches based on the outcomes of the past inventions. Thus, with more rigorous screening processes, collaboration teams can abandon or modify seemingly less fruitful configurations of knowledge components ex ante. Because the reducing number of unnecessary combination tries can ease inventors' burden of conducting complex inventing (Fleming \& Sorenson, 2004), the increasing size of collaboration teams is likely to weaken the negative effect of complexity from recombining highly coupled components. Thus, we suggest:

Hypothesis 2: As the size of a collaboration team involved in the development of an invention increases, the negative relationship between coupling and the likelihood of creating breakthrough inventions weakens.

\section{Oldness of Prior Art}

Because knowledge is created by referring to core ideas of existing knowledge, knowledge becomes cumulative and is shared and transferred (Zucker, Darby, \& Armstrong, 2002). Similarly, inventions are not created ex nihilo. They are mostly based on prior art. By referring to prior art, inventors can get the following help for inventing. First, they can search for potential components and untried configurations that are available at the time of inventing (Fleming, 2001). Second, they may know which configurations become technological dead ends (Podolny \& Stuart, 1995). In sum, inventors can manage inventing processes by referring to prior art related to their inventions.

However, prior art's history matter with inventing (Nerkar, 2003). Prior art that has been for a long period of time have been verified by many inventors in terms of its potential, limits, and so on. Therefore, old prior art is usually considered reliable (March, 1991). Relying on reliable prior art can decrease variance around inventing processes (Fleming, 2001) because it decreases the chances of trial-error-learning (Katila, 2002). Thus, referring to old prior art is likely to help to deal with highly coupled components:

Hypothesis 3: As older prior art is referenced for invention, the negative relationship between coupling and the likelihood of creating breakthrough inventions weakens.

\section{METHODS}

\section{Data and Sample}

Inventions exist in several forms (Schilling \& Green, 2011). Previous studies often regard patents as inventions (Arts \& Veugelers, 2015; Audia \& Goncalo, 2007; Fleming \& Sorenson, 2004; Schoenmakers \& Duysters, 2010; Singh \& Fleming, 2010). Therefore, patents are considered inventions in this study. In the U.S. patent system, patents are sorted 
into classification codes in terms of their technological similarity (Benner \& Waldfogel, 2008). Each patent must have one original classification code. Patents can also list additional classification codes called cross-reference classifications. A U.S. patent classification code is comprised of one class and one nested subclass. Classes reflect broad technology domains, and subclasses reflect knowledge components within a given technological domain (Arts \& Veugelers, 2015; Fleming, 2001; Fleming \& Sorenson, 2004). This reflectiveness of classes and subclasses makes it relatively easy to collect patents closely related to a specific industry or technology domain and to measure knowledge components-related variables such as coupling. Therefore, U.S. granted patents were used for the study.

Our empirical context is the optical disc industry during 1997-2001. Considering the optical disc industry during the period 1997-2001 presents three advantages for this study. First, the optical disc industry has diverse inventors and organizations that actively engage in patenting activity (Joshi \& Nerkar, 2011). Second, DVD technology standards were established in 1996 (Dranove \& Gandal, 2003), and the movement of setting the next generation technology Blu-ray - started after 2001. This means that, because the period 1997-2001 was influenced less by technology change, we can control for exogenous technology effects to some degree. Finally, industries vary in their patenting propensity. Thus, the restriction to a single industry limits industry-level heterogeneity (Audia \& Goncalo, 2007).

Based on the U.S. patent classification codes, we identified patent classes closely related to optical disc technologies by using essential patents of the two DVD patent pools: the DVD3C (Digital Versatile Disc 3 Companies) and the DVD6C (Digital Versatile Disc 6 Companies). A patent pool is a consortium of firms that aggregate their essential patents, defined as patents that comply with a technology standard, related to specific technologies or products to share these essential patents (cross-license) as well as to license them to non-participants (Joshi \& Nerkar, 2011). Because essential patents are technologically and commercially critical to relevant industries (Di Minin \& Bianchi, 2011; Rysman \& Simcoe, 2008), technology domains to which the essential patents of the two DVD patent pools belong can also be relevant in the optical disc industry.

We found that three classes $-369,375$, and $386^{1}$ - have more than one hundred essential patents of the DVD patent pools. We set these classes as technology domains closely related to optical disc technology. Subsequently, we gathered from the United States Patent and Trademark Office web site information on all granted patents that have at least one of the three optical disc classes in their own original classification codes and were applied during 19972001. The information includes the following: application year, grant year, reference patents (backward citations), forward citations, classification codes, claims, and inventors' name and country. The number of the collected patents is 17,564 . These patents are our sample patents.

\section{Dependent Variable and Analytic Approach}

This study defines breakthrough inventions as patents with disproportionately large impact on future patents (Arts \& Veugelers, 2015). Previous studies usually use forward citations to measure the impact of patents (Arts \& Veugelers, 2015; Fleming \& Sorenson, 2004). Backward citations of a patent are its prior art that is written in the patent's document to assert its uniqueness legally. Forward citations of a patent are patents citing it as their prior art. The number of forward citations a patent receives is closely associated with its technological importance and industry peers' perception of the relevance and innovative potential of the patented technologies (Gittelman \& Kogut, 2003; Jaffe, Trajtenberg, \& Henderson, 1993; Rosenkopf \& Nerkar, 2001). Thus, we interpreted the number of forward citations of a patent as its impact on future patents (Arts \& Veugelers, 2015; Fleming \& Sorenson, 2004). In the process of reviewing applications, patent examiners verify whether the list of backward citations is complete, which can make measures using citations nosy. However, bias resulting from nosy citations may not be necessarily an issue because both inventor citations and examiner citations track each other closely (Alcácer \& Gittelman, 2006). Therefore, following previous studies (Ahuja \& Lampert, 2001; Schoenmakers \& Duysters, 2010), we regarded breakthrough patents as those with the most number of forward citations.

\footnotetext{
${ }^{1}$ 369: Dynamic information storage ore retrieval; 375: Pulse or digital communications; 386: Motion video signal processing for recording or reproducing.
}

Copyright by author(s); $\underline{\mathrm{CC}-\mathrm{BY}}$ 
Older patents have a higher chance of receiving forward citations than younger ones (Schoenmakers \& Duysters, 2010). To deal with this problem, we counted forward citations that sample patents had received till ten years after their grant year. Because forward citations of a patent in general reach a plateau after three years from its application and patents are usually granted one to three years after application (Jaffe et al., 1993), the ten-year window can capture most forward citations of a patent. Second, we sorted the number of forward citations of sample patents based on their original class and application year. Finally, by using one percent cut off in terms of the number of forward citations in original technology class and application year groups (Ahuja \& Lampert, 2001), we made a dichotomy variable indicating one if a patent is under the cutoff and zero otherwise.

We estimated our empirical models by using logistic regression analysis because the dependent variable is a binary variable. We specified robust standard error to control for potential heteroskedasticity and to provide a more conservative test of our hypotheses.

\section{Independent Variables}

\section{Coupling}

We calculated the coupling of sample patents in two stages (Fleming \& Sorenson, 2001, 2004). Equation 1 measures the ease of recombination of individual subclass $j$ used in patent $i$.

$$
E_{j}=\frac{n s u b_{j}}{n p a t_{j}}(1)
$$

In equation $1, n s u b_{j}$ is the number of subclasses previously combined with subclass $\mathrm{j}$ during ten years before the application year of the patent $i$, and $n p a t_{j}$ is the number of all patents with the subclass $j$ granted during ten years before the application year of the patent $i$. To create the coupling of a patent, we inverted the mean of the ease of recombination scores for its subclasses as appeared in equation 2.

$$
\text { Coupling }_{i}=\frac{n s u b_{i}}{\sum_{j \in i} E_{j}}(2)
$$

\section{Size of Collaboration Team}

We made two variables indicating the size of collaboration teams. First, the number of inventors involved in a sample patent was included in our empirical models. Second, for further analyses, we made a dummy variable with one if the number of inventors greater than one or with zero otherwise (Singh \& Fleming, 2010).

\section{Oldness of Prior Art}

We measured the oldness of prior art by calculating the median age of backward citations (Heeley \& Jacobson, 2008). The age of a backward citation of a sample patent are years elapsed since its application year until the grant year of the sample patent.

\section{Control Variables}

Technology fixed effects were used to account for systematic differences of forward citation rates across different technology domains. We used original classes of sample patents to create technology fixed effects. Likewise, Year fixed effects were used to account for any systematic differences over years by using application years of sample patents.

We also included a variety of variables to control for technology-related heterogeneity. Patent pools' essential patents have a larger impact on future patents than non-essential patents (Rysman \& Simcoe, 2008). Thus, we made a dummy variable that equals one if a sample patent is essential in the DVD patent pools. Otherwise, it has zero. A few patents have no backward citations $(N=137)$. These patents may have novel ideas that previous patents did not cover. To 
control for this radicalness, we included a dummy variable, Backward citations, with one if a patent has backward citation(s) or with zero otherwise. Claims in a patent can be an indicator of efforts invested in the development of this patent (Tong \& Frame, 1994). So, we included Number of claims of a patent in our empirical models. We logged this variable due to its high skewness. As more knowledge components are included in inventing processes, inventors may have more challenges to manage interactions of these components (Maggitti et al., 2013). Therefore, we included the Number of subclasses by logging the variable. In our sample, the number of patents with single subclass is 771 . Although this figure is extremely small, our coupling measure may be not able to precisely capture combination processes with single component (Fleming \& Sorenson, 2004). Therefore, we included a dummy variable with one if a patent has single subclass and with zero otherwise. Finally, when a patent is related to several technology domains, it may receive more forward citations because future patents applied in these technology domains may refer to it (Fleming \& Sorenson, 2004). To control for this possible effect, we included the Number of classes of a patent in our empirical models.

\section{RESULTS}

Descriptive statistics and correlation matrix are reported in Table 1. Correlations between independent variables are relatively moderate, indicating that multicollinearity should not be a major concern. We also computed variance inflation factors (VIFs) for all variables and found relatively small VIF values below 10 (maximum VIF = 1.88; mean $\mathrm{VIF}=1.22)$ that is the rule-of-thumb cutoff of VIF (O'brien, 2007).

Table 1. Descriptive statistics and correlation matrix

\begin{tabular}{|c|c|c|c|c|c|c|c|c|c|c|}
\hline & 1 & 2 & 3 & 4 & 5 & 6 & 7 & 8 & 9 & 10 \\
\hline 1. . Breakthrough patent & & & & & & & & & & \\
\hline 2. Essential patent & 0.054 & & & & & & & & & \\
\hline 3. Backward citations & -0.005 & -0.001 & & & & & & & & \\
\hline 4. $\ln$ (Number of claims) & 0.054 & -0.085 & 0.008 & & & & & & & \\
\hline 5. $\ln$ (Number of subclasses) & 0.026 & 0.180 & -0.001 & -0.061 & & & & & & \\
\hline 6. Single subclass & -0.007 & -0.035 & 0.010 & 0.041 & -0.512 & & & & & \\
\hline 7. Number of classes & 0.002 & 0.058 & 0.002 & -0.044 & 0.469 & -0.261 & & & & \\
\hline 8. Coupling & -0.021 & -0.088 & 0.010 & 0.054 & -0.394 & 0.189 & -0.193 & & & \\
\hline 9. Number of inventors & 0.035 & 0.149 & -0.011 & 0.024 & 0.115 & -0.026 & 0.033 & -0.052 & & \\
\hline $\begin{array}{l}\text { 10. Median age of backward } \\
\text { citations }\end{array}$ & -0.018 & -0.036 & 0.245 & 0.023 & 0.096 & 0.064 & -0.018 & 0.089 & -0.041 & \\
\hline Mean & 0.010 & 0.028 & 0.992 & 2.580 & 1.492 & 0.044 & 1.989 & 0.475 & 2.345 & 8.404 \\
\hline S.D. & 0.098 & 0.165 & 0.088 & 0.805 & 0.624 & 0.205 & 0.812 & 0.176 & 1.657 & 3.043 \\
\hline Min & 0 & 0 & 0 & 0 & 0 & 0 & 1 & 0.084 & 1 & 0 \\
\hline Max & 1 & 1 & 1 & 6.390 & 3.932 & 1 & 7 & 1.726 & 18 & 52 \\
\hline
\end{tabular}

Notes: All correlations with absolute values greater than 0.020 are significant $(p<0.01)$.

Table 2 displays the results of logit analyses for our hypotheses. Mode 1 includes only control variables. Model 6 is a full model with all variables. Because the results of model 6 are not different with the results of other models, we mainly interpreted the results of model 6 . 
Table 2. Logit analysis of the creation of breakthrough patents

\begin{tabular}{|c|c|c|c|c|c|c|}
\hline & Model 1 & Model 2 & Model 3 & Model 4 & Model 5 & Model 6 \\
\hline Coupling & & $\begin{array}{l}-1.413^{*} \\
(0.620)\end{array}$ & $\begin{array}{l}-2.919 \\
(2.503)\end{array}$ & $\begin{array}{l}-3.097^{* * *} \\
(0.854)\end{array}$ & $\begin{array}{l}-2.271^{\dagger} \\
(1.303)\end{array}$ & $\begin{array}{l}-3.970^{* *} \\
(1.395)\end{array}$ \\
\hline Coupling $^{2}$ & & & $\begin{array}{c}1.412 \\
(2.366) \\
\end{array}$ & & & \\
\hline Number of inventors & & & & $\begin{array}{l}-0.168 \\
(0.108)\end{array}$ & & $\begin{array}{l}-0.170 \\
(0.108)\end{array}$ \\
\hline Median age of backward citations & & & & & $\begin{array}{l}-0.108 \\
(0.074)\end{array}$ & $\begin{array}{l}-0.107 \\
(0.076)\end{array}$ \\
\hline Coupling $\times$ Number of inventors & & & & $\begin{array}{c}0.598^{* *} \\
(0.208)\end{array}$ & & $\begin{array}{c}0.598^{* *} \\
(0.207)\end{array}$ \\
\hline Coupling $\times$ Median age of backward citations & & & & & $\begin{array}{c}0.108 \\
(0.144)\end{array}$ & $\begin{array}{c}0.111 \\
(0.152)\end{array}$ \\
\hline Technology fixed effects & Included & Included & Included & Included & Included & Included \\
\hline Year fixed effects & Included & Included & Included & Included & Included & Included \\
\hline Essential patent & $\begin{array}{l}1_{1.901^{* * *}} \\
(0.278)\end{array}$ & $\begin{array}{l}1.939^{\text {*** }} \\
(0.274)\end{array}$ & $\begin{array}{l}1.952^{* * *} \\
(0.274)\end{array}$ & $\begin{array}{l}1.877^{* * *} \\
(0.278)\end{array}$ & $\begin{array}{l}1.928^{* * *} \\
(0.276)\end{array}$ & $\begin{array}{l}1.867^{* * *} \\
(0.281)\end{array}$ \\
\hline Backward citations & $\begin{array}{l}-0.456 \\
(0.733)\end{array}$ & $\begin{array}{l}-0.446 \\
(0.734)\end{array}$ & $\begin{array}{l}-0.454 \\
(0.734)\end{array}$ & $\begin{array}{l}-0.428 \\
(0.734)\end{array}$ & $\begin{array}{c}0.046 \\
(0.773)\end{array}$ & $\begin{array}{c}0.046 \\
(0.771)\end{array}$ \\
\hline $\ln$ (Number of claims) & $\begin{array}{l}0.840^{* * *} \\
(0.120)\end{array}$ & $\begin{array}{l}0.836^{* * *} \\
(0.120)\end{array}$ & $\begin{array}{l}0.835^{* * *} \\
(0.119)\end{array}$ & $\begin{array}{l}0.817^{* * *} \\
(0.118)\end{array}$ & $\begin{array}{l}0.841^{* * *} \\
(0.122)\end{array}$ & $\begin{array}{l}0.822^{* * *} \\
(0.120)\end{array}$ \\
\hline $\ln$ (Number of subclasses) & $\begin{array}{c}0.493^{* *} \\
(0.151)\end{array}$ & $\begin{array}{c}0.380^{*} \\
(0.151)\end{array}$ & $\begin{array}{c}0.379^{*} \\
(0.150)\end{array}$ & $\begin{array}{c}0.357^{*} \\
(0.152)\end{array}$ & $\begin{array}{c}0.358^{*} \\
(0.153)\end{array}$ & $\begin{array}{c}0.337^{*} \\
(0.153)\end{array}$ \\
\hline Single subclass & $\begin{array}{c}0.184 \\
(0.512)\end{array}$ & $\begin{array}{c}0.163 \\
(0.513)\end{array}$ & $\begin{array}{c}0.141 \\
(0.501)\end{array}$ & $\begin{array}{c}0.092 \\
(0.526)\end{array}$ & $\begin{array}{c}0.161 \\
(0.512)\end{array}$ & $\begin{array}{c}0.093 \\
(0.525)\end{array}$ \\
\hline Number of classes & $\begin{array}{l}-0.089 \\
(0.103)\end{array}$ & $\begin{array}{l}-0.077 \\
(0.101)\end{array}$ & $\begin{array}{l}-0.075 \\
(0.101)\end{array}$ & $\begin{array}{l}-0.069 \\
(0.101)\end{array}$ & $\begin{array}{l}-0.062 \\
(0.101)\end{array}$ & $\begin{array}{l}-0.054 \\
(0.101)\end{array}$ \\
\hline Constant & $\begin{array}{l}-7.885^{* * *} \\
(0.866)\end{array}$ & $\begin{array}{l}-7.138^{* * *} \\
(0.904)\end{array}$ & $\begin{array}{l}-6.799^{* * *} \\
(0.988)\end{array}$ & $\begin{array}{l}-3.097^{* * *} \\
(0.854)\end{array}$ & $\begin{array}{l}-6.725^{* * *} \\
(0.945)\end{array}$ & $\begin{array}{l}-6.203^{\text {*** }} \\
(0.970)\end{array}$ \\
\hline Obs. & 17,564 & 17,564 & 17,564 & 17,564 & 17,564 & 17,564 \\
\hline Wald $\chi^{2}(d . f)$. & $136.2(12)$ & $140.4(13)$ & $142.6(14)$ & $160.8(15)$ & $139.3(15)$ & $161.5(17)$ \\
\hline
\end{tabular}

$\dagger: p<.10 ;^{*}: p<.05 ;{ }^{* *}: p<.01 ; * * *: p<.001$; Robust standard error in parentheses.

The most results of control variables in model 6 are similar to those of previous studies. One interesting result is the positive effect of $\ln$ (Number of subclasses) on the creation of breakthrough inventions. Given that earlier studies imply the negative effect of the number of subclasses on inventing processes (Maggitti et al., 2013), the positive effect of $\ln$ (Number of subclasses) in model 6 may indicate an inverted-U relationship between $\ln$ (Number of subclasses) and the creation of breakthrough inventions. The square term of $\ln$ (Number of subclasses) in an additional analysis showed a negative sign but was not statistically significant.

We predicted that coupling has a negative effect on the creation of breakthrough inventions. In keeping with this hypothesis, the coefficient of coupling is negative and statistically significant $(\beta=-3.970 ; p<.01)$. As some studies suggest that inventors may find superior configurations of knowledge components luckily during complex inventing (e.g. Fleming \& Sorenson, 2004), the relationship between coupling and the creation of breakthrough inventions may be non-linear. We tested the non-linear relationship in model 3, but the square term of coupling is not statistically significant.

The coefficient of the interaction variable of coupling and the number of inventors is positive and statistically significant $(\beta=0.598 ; p<.01)$, which confirms hypothesis 2 that, as the number of inventors involved in the development of inventions increases, the negative relationship between coupling and the creation of breakthrough inventions weakens. We also verified the moderating effect of collaboration by using a collaboration dummy variable (Singh \& Fleming, 2010). Although not reported in this study, the collaboration dummy variable showed a significant moderating effect with positive sign $(\beta=2.617 ; p<.05)$. These results indicate that collaboration among inventors is one of the useful ways to manage complexity emerging from combining highly coupled components. 
Finally, we tested the interaction effect of coupling and the median age of backward citations to test hypothesis 3 . The empirical results show that the interaction term of coupling and the median age of backward citations has nonsignificant moderating effect. We also tested the interaction term with the mean age of backward citations but did not find any significant coefficient. Thus, hypothesis 3 is not supported.

\section{DISCUSSION AND CONCLUSION}

Knowledge creation is sometimes highly complex (Nickerson \& Zenger, 2004). Inventors point out the complexity of inventing as one of the obstacles to creating useful inventions (Maggitti et al., 2013). Thus, it is critical to examine the effects of complex inventing on the creation of breakthrough inventions and to identify ways to reduce the complexity of inventing. This study argues the negative effect of coupling, the aggregated interdependencies in knowledge components, on the likelihood of creating breakthrough inventions and suggests two factors weakening the negative effect of coupling: the size of collaboration teams and the oldness of prior art. Based on U.S. granted patents in optical disc technology domains applied during 1997-2001, we found the negative effect of coupling on the likelihood of creating breakthrough patents and the weakening moderating effect of the number of inventors involved in the development of patents.

One interesting finding is that referring to old prior art is not likely to be helpful for reducing the complexity of inventing. This study argues that the reliability of referenced old prior art is important in the creation of breakthrough inventions with highly coupled components. One possible explanation is that the reliability of extant knowledge is not correlated with its oldness. Thus, it would be interesting for future studies to consider other measures of the reliability of knowledge when focusing on complex inventing.

A few papers have suggested ways to manage complex inventing. For example, Fleming and Sorenson (2004) showed that referring to science articles can reduce complexity resulting from the coupling of inventions. Maggitti et al. (2013) suggested several methods to manage complex inventing through a qualitative approach. However, these studies did not focus on the role of collaboration in managing complex inventing. Thus, this study contributes to research on invention by suggesting the positive role of collaboration in creating breakthrough inventions with highly coupled components.

Given that managing the processes of creating breakthrough inventions is critical to firm practitioners (Maggitti et al., 2013; Schoenmakers \& Duysters, 2010), our study provides some managerial implications. Collaboration teams not only promote the creativity of team members (Singh \& Fleming, 2010) but also help managing complex inventing. Thus, when initiating the development of inventions, R\&D managers should utilize collaboration teams to reduce the complexity of inventing and to increase the possibility of creating of breakthrough inventions. Or, as we argued the diverse knowledge and experience of collaboration teams as one of the main causes of reducing the complexity of inventing, given the critical role of hubs connecting groups in problem-solving processes such as invention (Schilling $\&$ Fang, 2014), it may be necessary to include inventors in inventing processes that can interact with other invention teams within a firm to leverage diverse knowledge and experience embedded in them.

Our study has some limitations. First, among various forms of invention (Schilling \& Green, 2011), we focus on only patents. Although earlier studies regarded patents as inventions (Arts \& Veugelers, 2015; Audia \& Goncalo, 2007; Fleming \& Sorenson, 2004; Schoenmakers \& Duysters, 2010; Singh \& Fleming, 2010), it will be interesting to consider complexity associated with other forms of invention. Second, the coupling of knowledge components is one dimension of complex inventing (Maggitti et al., 2013). We do not consider the relationship between the other dimensions of complex inventing and the creation of breakthrough inventions. Finally, the empirical results might reflect factors specific to the optical disc industry. Although the restriction to a single industry limits unobserved heterogeneity and enables researchers to implement more systematic and unbiased comparisons of results, the replication and elaboration of this study in other settings would be useful. 


\section{ACKNOWLEDGEMENTS}

This work was supported by the National Research Foundation of Korea Grant funded by the Korean Government (NRF-2014S1A3A2044046).

\section{AUTHOR BIOGRAPHIES}

Hee Jin Mun is a postdoctoral researcher in the Institute of Convergence Science at Yonsei University. Research interests are internationalization of high-tech firms and organizational learning. E-mail: heejin.mun@yonsei.ac.kr

Yerim Chung is an assistant professor in School of Business at Yonsei University. Research interests are network topology and network effects. yerimchung@yonsei.ac.kr (corresponding author)

\section{REFERENCES}

Ahuja, G., \& Lampert, C. M. (2001). Entrepreneurship in the large corporation: A longitudinal study of how established firms create breakthrough inventions. Strategic Management Journal, 22(6-7), 521-543.

Alcácer, J., \& Gittelman, M. (2006). Patent citations as a measure of knowledge flows: The influence of examiner citations. Review of Economics and Statistics, 88(4), 774-779.

Arts, S., \& Veugelers, R. (2015). Technology familiarity, recombinant novelty, and breakthrough invention. Industrial and Corporate Change, 24(6), 1215-1246.

Audia, P. G., \& Goncalo, J. A. (2007). Past success and creativity over time: A study of inventors in the hard disk drive industry. Management Science, 53(1), 1-15.

Benner, M., \& Waldfogel, J. (2008). Close to you? Bias and precision in patent-based measures of technological proximity. Research Policy, 37(9), 1556-1567.

Brusoni, S., Prencipe, A., \& Pavitt, K. (2001). Knowledge specialization, organizational coupling, and the boundaries of the firm: Why do firms know more than they make? Administrative Science Quarterly, 46(4), 597-621.

Di Minin, A., \& Bianchi, M. (2011). Safe nests in global nets: Internationalization and appropriability of R\&D in wireless telecom. Journal of International Business Studies, 42(7), 910-934.

Dranove, D., \& Gandal, N. (2003). The Dvd-vs.-Divx standard war: Empirical evidence of network effects and preannouncement effects. Journal of Economics \& Management Strategy, 12(3), 363-386.

Fleming, L. (2001). Recombinant uncertainty in technological search. Management Science, 41(1), 117-132.

Fleming, L., \& Sorenson, O. (2001). Technology as a complex adaptive system: Evidence from patent data. Research Policy, 30(7), 1019-1039.

Fleming, L., \& Sorenson, O. (2004). Science as a map in technological search. Strategic Management Journal, 25(8-9), 909928.

Gavetti, G., \& Levinthal, D. A. (2000). Looking forward and looking backward: Cognitive and experiential search. Administrative Science Quarterly, 45(1), 113-137.

Gittelman, M., \& Kogut, B. (2003). Does good science lead to valuable knowledge? Biotechnology firms and the evolutionary logic of citation patterns. Organization Science, 49(4), 366-382.

Heeley, M. B., \& Jacobson, R. (2008). The recency of technological inputs and financial performance. Strategic Management Journal, 29(7), 723-744.

Jaffe, A. B., Trajtenberg, M., \& Henderson, R. (1993). Geographic localization of knowledge spillovers as evidenced by patent citations. Quarterly Journal of Economics, 108(3), 577-598.

Joshi, A. M., \& Nerkar, A. (2011). When do strategic alliances inhibit innovation by firms? Evidence from patent pools in the global optical disc industry. Strategic Management Journal, 32(11), 1139-1160.

Katila, R. (2002). New product search over time: Past ideas in their prime? Academy of Management Journal, 45(5), 95-1010.

Maggitti, P. G., Smith, K. G., \& Katila, R. (2013). The complex search process of invention. Research Policy, 42(1), 90-100.

March, J. G. (1991). Exploration and exploitation in organizational learning. Organization Science, 2(1), 71-87.

March, J. G., \& Simon, H. A. (1993). Organizations (2nd ed.). Cambridge, MA: Blackwell.

Nelson, R. R., \& Winter, S. G. (1982). An Evolutionary Theory of Economic Change. Cambridge, MA: The Belknap Press of Harvard University Press.

Nerkar, A. (2003). Old Is gold? The value of temporal exploration in the creation of new knowledge. Management Science, 49(2), 211-229.

Nickerson, J. A., \& Zenger, T. R. (2004). A knowledge-based theory of the firm - The problem-solving perspective. Organization Science, 15(6), 617-632.

Nonaka, I. (1994). A dynamic theory of organizational knowledge creation. Organization Science, 5(1), 14-37. 
O'brien, R. M. (2007). A caution regarding rules of thumb for variance inflation factors. Quality \& Quantity, 41(5), 673-690.

Podolny, J. M., \& Stuart, T. E. (1995). A role-based ecology of technological change. American Journal of Sociology, 100(5), $1224-1260$.

Rosenkopf, L., \& Nerkar, A. (2001). Beyond local search: Boundary-spanning, exploration, and impact in the optical disk industry. Strategic Management Journal, 22(4), 287-306.

Rysman, M., \& Simcoe, T. (2008). Patents and the performance of voluntary standard-setting organizations. Management Science, 54(11), 1920-1934.

Schilling, M. A., \& Fang, C. (2014). When hubs forget, lie, and play favorites: Interpersonal network structure, information distortion, and organizational learning. Strategic Management Journal, 35(7), 974-994.

Schilling, M. A., \& Green, E. (2011). Recombinant search and breakthrough idea generation: An analysis of high impact papers in the social sciences. Research Policy, 40(10), 1321-1331.

Schoenmakers, W., \& Duysters, G. (2010). The technological origins of radical inventions. Research Policy, 39(8), $1051-1059$.

Singh, J., \& Fleming, L. (2010). Lone inventors as sources of breakthroughs: Myth or reality? Management Science, 56(1), 4156.

Taylor, A., \& Greve, H. R. (2006). Superman or the fantastic four? Knowledge combination and experience in innovative teams. Academy of Management Journal, 49(4), 723-740.

Tong, X., \& Frame, J. D. (1994). Measuring national technological performance with patent claims data. Research Policy, 23(2), $133-141$.

Yayavaram, S., \& Ahuja, G. (2008). Decomposability in knowledge structures and its impact on the usefulness of inventions and knowledge-base malleability. Administrative Science Quarterly, 53(2), 333-362.

Zucker, L. G., Darby, M. R., \& Armstrong, J. S. (2002). Commercializing knowledge: University science, knowledge capture, and firm performance in biotechnology. Management Science, 48(1), 138-153. 